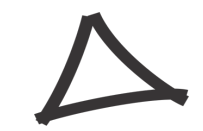

Revista Triângulo

\title{
SAÚDE, FORÇA E ALEGRIA: OS PELOTÕES DE SAÚDE E AS CRUZADAS HIGIENISTAS EM TEMPOS DE NACIONALISMO (1941-1953)
}

\author{
HEALTH, STRENGTH AND JOY: THE HEALTH GROUPS AND \\ THE CROSSED HYGIENISTS IN TIMES OF NATIONALISM (1941-1953)
}

\section{SALUD, FUERZA Y ALEGRIA: LOS PELOTONES DE SALUD Y LAS CRUZADAS DE HIGIENE EM TIEMPOS DE NACIONALISMO (1941-1953)}

\author{
Michele Metelski \\ Universidade do Estado de Santa Catarina \\ E-mail: profissionalmichele@hotmail.com
}

\author{
Celso João Carminati \\ Universidade do Estado de Santa Catarina \\ E-mail: cjcarminati@gmail.com
}

\begin{abstract}
RESUMO
Este trabalho apresenta a história dos pelotões da saúde constituídos em escolas de Santa Catarina a partir do ano de 1941. Baseado em documentos significativos, tais como atas, relatórios anuais, relatórios mensais e reuniões pedagógicas encontrados no Arquivo Público do Estado de Santa Catarina, apresenta o lugar das escolas e as campanhas voltadas às crianças de escolas primárias. Destaca a criação desses pelotões, que faziam parte das associações auxiliares das escolas estaduais, inicialmente presentes em 75 delas, como grupos escolares, escolas mistas municipais, isoladas, mistas, municipais, estaduais, escolas mistas desdobradas, escolas femininas estaduais, colégios particulares e escolas públicas estaduais. Campanhas de saúde foram promovidas; como as escolas passaram a ser um espaço de divulgação, formação e consolidação de hábitos, certamente contribuiriam para a disseminação de informações e orientações que alcançariam toda a família. O controle dos hábitos saudáveis ao corpo era condição fundamental para a formação de civilidades e valores para a disseminação de novas práticas higienistas.
\end{abstract}

PALAVRAS-CHAVE: Pelotão de Saúde. História da Educação. Higiene.

\begin{abstract}
Based on significant documents, such as minutes, annual reports, monthly reports and pedagogical meetings found in the Public Archives of the State of Santa Catarina, this paper presents the history of the health platoons constituted in schools of Santa Catarina from the year 1941. The place of schools and campaigns directed at primary school children. Of particular note was the creation of these platoons, which were part of the auxiliary associations of the state schools, initially present in 75 of them, such as school groups, mixed municipal schools, isolated, mixed, municipal, state, mixed schools, state schools, private colleges and schools of the state. Health campaigns were promoted; as schools became a space for dissemination, formation and consolidation of habits, would certainly contribute to the dissemination of information and guidance that would reach the whole family. The control of healthy habits to the body was a fundamental condition for the formation of civilities and values for the dissemination of new hygienic practices.
\end{abstract}

KEYWORDS: Health Platoon. History of Education. Hygiene. 


\section{RESUMEN}

Este trabajo presenta la historia de los pelotones de la salud constituidos en escuelas de Santa Catarina a partir del año 1941. Basado en documentos significativos, tales como actas, informes anuales, informes mensuales y reuniones pedagógicas encontradas en el Archivo Público del Estado de Santa Catarina, presenta el lugar de las escuelas y las campañas dirigidas a los niños de escuelas primarias. En el caso de las escuelas secundarias, las escuelas secundarias, las escuelas mixtas municipales, aisladas, mixtas, municipales, estatales, escuelas mixtas desplegadas, escuelas femeninas estatales, colegios privados y escuelas públicas estatales. Se promovieron campañas de salud; como las escuelas pasaron a ser un espacio de divulgación, formación y consolidación de hábitos, ciertamente contribuirían a la diseminación de informaciones y orientaciones que alcanzarían a toda la familia. El control de los hábitos saludables al cuerpo era condición fundamental para la formación de civilidades y valores para la diseminación de nuevas prácticas higienistas.

PALABRAS CLAVE: Pelotón de Salud. Historia de la Educación. Higiene.

\section{INTRODUÇÃO}

Em prol de um Brasil cada vez mais belo e saudável: tudo faremos pelo seu engrandecimento.

(SANTA CATARINA, 1941)

Ao apresentar as novas práticas de formação dos alunos em escolas catarinenses, compreendemos os sentidos que permeiam as bases da constituição de um ideário e de um ethos higienista capaz de transformar, pela via da escola e da educação, o disciplinamento das crianças com relação às práticas de higiene e aos hábitos familiares, em geral.

A introdução das campanhas, mediante o slogan "Pelotões de saúde", traz os sentidos expressos nos grupos selecionados, treinados e destinados à visitação dos estabelecimentos escolares para disseminar a iniciativa de práticas de conduta com vistas às normas de asseio do corpo e evitar a proliferação de doenças consideradas de fácil controle, reduzindo, dessa forma, a mortalidade da população. Pelo disciplinamento dos corpos, essas campanhas se faziam de cidade em cidade com o objetivo de orientar os alunos das mais variadas idades acerca dos cuidados necessários à saúde e, para isso, ao disciplinamento do corpo.

Diante de uma realidade de calamidade de saúde, corpos saudáveis eram condições basilares para o bom funcionamento das escolas e para a aprendizagem das crianças. As iniciativas nas escolas baseavam-se no tripé que sustentava as campanhas do governo catarinense: saúde, força e alegria. Com a higienização, seria possível formar um novo cidadão, capaz de ver nos símbolos da campanha o emblema da representação do compromisso público com o governo e consolidar o espírito patriótico pela querida terra natal 
de todos os brasileiros, capaz de acolhê-los indistintamente. Na base da discussão, não podemos deixar de conferir a posição de destaque ocupada para fins de consolidação do espírito patriótico. Após o lançamento das campanhas, porém, constatava-se que muitas escolas não recebiam os subsídios para lhes dar continuidade, evidenciando-se a necessidade de articular amplos apelos à comunidade para que auxiliasse na aquisição de medicamentos para encaminhamento às escolas e às famílias (SANTA CATARINA, 1941).

Assim, tomando como ponto de partida a documentação histórica, dialogamos com as fontes para compreender e mostrar as diferentes formas de entender a educação e o papel das escolas nessas campanhas. Desenvolveremos o tema por partes, ou assunto.

\section{Aspectos iniciais: dos objetivos às cruzadas higienistas}

No início do século $\mathrm{XX}$, os médicos higienistas criaram uma proposta de educação que abrangia a consciência sanitária coletiva dos brasileiros. Para atingir os principais objetivos da cruzada, foi necessário propor um alvo, focar em algo que representasse o campo mais fácil para disseminar seus preceitos, algo novo, que oferecesse plasticidade moldável, um lugar que acomodasse a fase pueril, momento mais propício à inculcação de novos hábitos, ou seja, a escola primária, ou a casa da escola, como podemos ler na citação a seguir:

\footnotetext{
Bons hábitos exercem grande influência, tanto na vida prática, como moral e intelectual. Necessários à vida prática, são hábitos de ordem, higiene, o trabalho sério, da economia, que dão à família certo bem-estar, preservando-a da miséria. Na vida intelectual, os hábitos de atenção reflexão são a fonte do progresso científico. $\mathrm{Na}$ vida moral, formam homens de verdadeiro valor, que serão o orgulho da nossa nação (SANTA CATARINA, 1941, p. 432).
}

Criar uma nova cultura higiênica garantiria a adoção de práticas comuns à vida de qualquer pessoa civilizada. O discurso médico, porém, alcançava maiores proporções, uma vez que, no pano de fundo, tudo se destinava a um objetivo maior, o trabalho eficiente de uma futura nação que serviria às economias capitalistas contemporâneas. Era incompreensível formar uma nação política, econômica e social forte sem preparar a criança, especialmente a pequena, para ser saudável. Era impossível pensar nessa questão sem a preparar para tal efeito. Valendo-se deste ideário, os discursos higienistas justificavam que a 
escola era o cenário ideal para tais práticas, uma vez que lá se apresentavam pessoas de lugares variados e de classes sociais diferentes:

\begin{abstract}
Os médicos, como intelectuais, autodelegaram-se a missão de higienizar a sociedade, mais particularmente, higienizar por meio da educação, elegendo a escola locus privilegiado de sua intervenção. Ao se apresentarem como promotores de uma possível ruptura com o passado colonial, operaram um ideário de construção de uma "nova escola" (LAROCCA, 2009, p. 14).
\end{abstract}

A aproximação da escola com a saúde oferecia responsabilidades sociais mais amplas. Além da preocupação com o letramento eficiente, indispensável à leitura dos preceitos médicos, a escola passou a se preocupar com a qualidade da educação, com a saúde, a alimentação, a higiene, etc. O campo médico organizou-se através de campanhas higienistas, de congressos, publicações de teses, e criou vários meios de representação junto à sociedade.

De acordo com Souza (2008), a crença no poder da escola tornou-se uma representação amplamente disseminada e compartilhada na sociedade brasileira no início de século XX. À escola primária foram atribuídas inúmeras finalidades, como, por exemplo, moldar o caráter das crianças, futuros trabalhadores do país, incutindo-lhes especialmente valores e virtudes morais, normas de civilidade, o amor ao trabalho, o respeito pelos superiores, o apreço pela pontualidade, pela ordem e pelo asseio. A escola popular deveria, de modo muito especial, colaborar na importantíssima obra da consolidação da nação brasileira, veiculando valores cívico-patrióticos, por meio das quais cultivaria nas novas gerações o amor à pátria.

Na década de 1940, na capital catarinense a saúde era precária. Mais de $80 \%$ da população era doente; a mortalidade infantil era gritante. Estudos sobre a higiene da infância foram abordados por Gondra (2004). Este autor analisa as teses dos alunos de medicina da Academia Imperial. As teses defendidas por médicos de vários estados brasileiros influenciaram também as questões higiênicas do estado de Santa Catarina. A these escrita por Oswaldo Cabral, em 1929, Problemas educacionais de Hygiene, expõe questões abrangentes sobre a higiene dos catarinenses. Para Cabral, a escola seria o caminho mais eficiente para instruir e educar higienicamente a infância no estado. Na percepção do autor, seria impossível educar a população para adquirir hábitos saudáveis de higiene exclusivamente por meio de 
campanhas e propagandas, uma vez que o número de analfabetos era enorme. Segundo o autor:

É preciso mudar o estado das coisas, tomando-se providências por meio de "uma medida de salvação". Essa medida evidenciava a escola como território fértil e central: "E esta reside no se procurar, antes de mais nada, preparar a geração vindoura" (CABRAL, 1929, p. 27).

Para Cabral, a criação de hábitos de higiene através da família era ineficiente. Era na escola que esses hábitos deveriam ser ensinados para que as próprias crianças pudessem disseminar junto às suas famílias o que aprendiam. Claro que estas observações não se aplicavam às crianças mais abastadas, preservadas da ignorância, que viviam nos grandes centros urbanos. Como as crianças poderiam aprender hábitos saudáveis com suas famílias se elas não os possuíam?

Segundo Bastos e Silva (1953), a educação sanitária procurava dar ao homem uma compreensão clara sobre a consciência sanitária, levando a toda comunidade o conceito de saúde como norma de bem-estar e de solidariedade social, incluindo as escolas primárias.

Devido às inúmeras mudanças sociais, políticas e econômicas por que passava o Brasil no início do século XX, ainda havia, entre outras coisas, a ameaça sanitária e epidêmica a ser resolvida. As classes dirigentes sentiam necessidade de soluções rápidas para as doenças que assolavam os núcleos urbanos e que começavam a ameaçar a força de trabalho e a expansão das atividades capitalistas. O higienismo entrou como uma solução controladora, em concordância com o pensamento republicano, que considerava as escolas um meio de inculcar os hábitos com vistas a um projeto educativo exemplar.

A Fundação Rockfeller, instituição estadunidense, desenvolveu, no período de 1916 a 1942, atividades importantes para controlar as principais epidemias que ocorriam no Brasil; porém, não bastava apenas ensinar a teoria. Era necessário colocar em prática os ensinamentos da higiene. No campo da educação, especificamente, destacamos o trabalho de Carlos Sá e César Leal Ferreira, que criaram, no ano de 1924, em São Gonçalo, no estado do Rio de Janeiro, o primeiro pelotão de saúde em uma escola estadual. 
O processo de nacionalização no estado de Santa Catarina intensificou-se a partir do Decreto-Lei ${ }^{\circ}$ 88, de 31 de março de 1938, baixado pelo interventor do estado, dr. Nereu de Oliveira Ramos, que voltava suas preocupações à formação dos brasileiros. O Departamento de Educação do Estado definiu as seguintes associações auxiliares da escola para fazer parte desse processo: clube agrícola, museu escolar, clube da leitura, pelotão de saúde, jornal escolar, círculo de pais e professores, centros de interesse, liga da bondade, pró-língua nacional e orfeão escolar.

Os pelotões de saúde fizeram parte do plano nacionalista organizado pelo Estado. O ideário dos pelotões bebia da fonte do discurso médico higienista e essas associações agiam em conjunto. Barbieri (1973, p. 237) classifica as associações em "peri-escolares, intraescolares e assistenciais". As peri-escolares são híbridas: escola e família, por exemplo; da mesma forma, as associações de pais e professores (Apps) e os círculos de pais e mestres. As intra-escolares tentam educar pela própria ação e pela prática dos alunos desenvolvidas em território escolar, envolvendo alunos e professores. As assistenciais buscavam suprir as necessidades dos professores, enquadrando as assistências médicas, dentárias e também as caixas escolares.

Figura 1: Representação de um aluno segurando a bandeira do Pelotão de Saúde

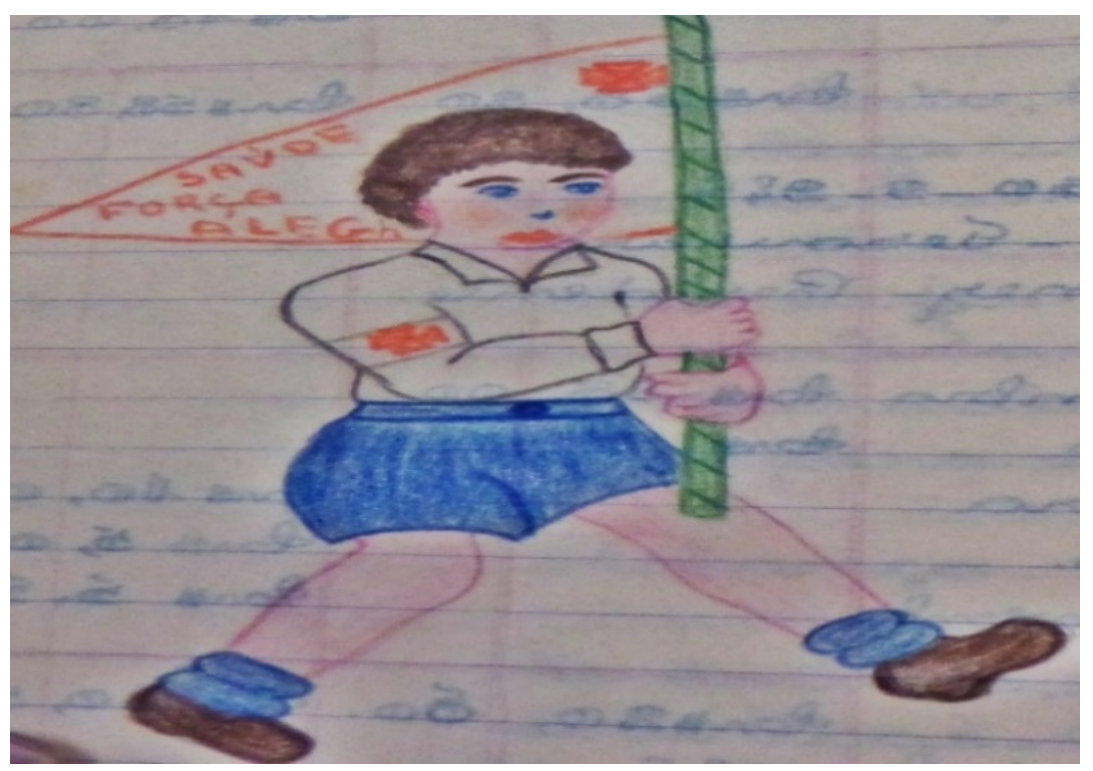

Fonte: Relatórios dos Pelotões de Saúde, 1942, p.67.

Localização: Acervo Apesc. 
Seguindo o exemplo do pelotão de saúde criado em 1924 no Rio de Janeiro, alguns estados começaram a implantar a associação como meio de disseminação das práticas higiênicas nas escolas, pois o combate às doenças constituía parte integrante do cotidiano escolar. A ideia de criar associações representava o coletivo, a junção de todos em função de um objetivo maior.

Os pelotões de saúde criados no estado de Santa Catarina surgiram no início do século XX. Nessa época, chegava às escolas um grande número de crianças de várias origens. Entendidos como uma ameaça, a ordem era civilizar, educar e moralizar. Orestes Guimarães, professor contratado pelo estado para reformar e modernizador a escola, dizia, a respeito das normas de higiene:

Um dos pré-requisitos para que a escola primária cumprisse a sua função de higienizar/educar/moralizar, as questões relacionadas à higiene e também à educação moral e cívica. [...] a presença dos pelotões de saúde nos grupos escolares, criados para intensificar o controle sobre o asseio dos corpos e das roupas e também para consolidar formas de comportamento consideradas válidas (TEIVE, 2008, p. 93).

Os pelotões de saúde, constituídos já no período do Estado Novo e em conformidade com a Constituição de 1937, seguiam a atuação do Estado que tinha o dever de colaborar com o acesso às instituições e à formação dos alunos em arte e ciência, assim como o acesso ao ensino primário obrigatório e gratuito. Nesse plano, os mais abastados tinham a obrigação de ajudar os mais necessitados, mesmo que de forma modesta, contribuindo mensalmente através da caixa escolar ${ }^{1}$.

Todo o processo de nacionalização do ensino percorreu caminhos diferenciados em cada estado brasileiro. Em Santa Catarina, a gestão do governador Nereu Ramos fundamentou- se no movimento nacionalista, que dava prioridade à escola, ressaltando que a boa educação e um corpo saudável eram pré-requisitos para a formação da nacionalidade brasileira. No centro de suas políticas, a prioridade era "despertar na criança o amor e o carinho pela natureza, e o verdadeiro patriotismo pela nossa terra natal que é o Brasil”

\footnotetext{
${ }^{1}$ Associação Escolar criada pelo Estado de Santa Catarina no ano de 1916.
} 
(SANTA CATARINA, 1945, p. 24). Na reunião realizada na cidade de Porto União, em maio de 1944, o inspetor Germano Wagenfuhr falou sobre a nacionalização:

[...] não se deve esquecer que estamos numa zona de nacionalização e que para realizar este trabalho grandioso que a pátria nos incumbiu é preciso conservar toda a integridade do nosso caráter, unindo-vos numa só força contra os elementos que desejarem lançar o pomo da discórdia entre nós, prejudicando nossas atividades, de mestres e nacionalizadores. Que a nacionalização, porém, não fique apenas no ambiente da escola, que vá mais além, até os lares dos educandos. Começaremos por atrair a escola, nas festas, reuniões de pais e mestres e demais atividades, os pais de alunos e as famílias. Procuremo-los; sempre que possível, não os isolar; vivamos em contacto com a sociedade local, porém dentro dos princípios fundamentais da nossa missão de educadores, transmitindo-lhes princípios e bases sociais, nacionalizando-os, principalmente o trabalho do professor, nesta zona, vai além da sua obrigação no estabelecimento. As associações escolares estão cumprindo a sua finalidade (SANTA CATARINA, 1944).

Além disso, é importante destacar a atuação das professoras primárias como verdadeiras disseminadoras das noções e conceitos de higiene no início do Século XX:

No conjunto das iniciativas de formação do novo campo, as professoras primárias foram vistas como importantes aliadas na obra de divulgação das noções de higiene. Nas justificativas para a escolha das normalistas, é recorrente a afirmação de ter sido essa solução engendrada em função da falta de enfermeiras formadas. As professoras atuaram como visitadoras sanitárias dos serviços de saúde estaduais até serem substituídas, gradativamente, por profissionais com formação e treinamento em saúde pública. A primeira turma contou com dezesseis moças. A justificativa para a opção pelas professoras primárias pôs em destaque a importância da formação pedagógica (FARIA, 2006, p. 187).

Como parte integrante do projeto nacionalista, os pelotões de saúde fizeram parte das associações auxiliares das escolas, 2.427 em sua totalidade; porém, encontramos registros documentais de apenas $75^{2}$ pelotões de saúde instalados nas escolas do estado no ano de 1941, a partir de 1944, após a publicação do Decreto n. 2.991 de 28 de abril, o número de pelotões de saúde aumentou significativamente. Tais escolas se distribuíam pelos centros urbanos e rurais e sob diversas denominações: grupos escolares, escolas mistas municipais, escolas mistas estaduais, escolas estaduais, escolas isoladas mistas municipais, escolas isoladas mistas estaduais, escolas mistas desdobradas, escolas femininas estaduais, escolas isoladas estaduais, colégios particulares, escolas públicas estaduais.

\footnotetext{
${ }^{2}$ Os documentos nos permitem chegar a esse número; não há mais dados no Arquivo Público de Santa Catarina.
} 
O diretor interino do Departamento de Educação, Elpídio Barbosa, estabeleceu finalidades para os pelotões da saúde. Essas foram expressas na circular $n^{\circ} 26$, de 19 de março de 1941, destinada aos inspetores escolares, diretores de grupos escolares e professores de escolas isoladas. De acordo com a circular, o ensino da higiene e a educação sanitária poderia ser feito "sob a forma ativa, pelos pelotões de saúde, constituindo-se os próprios alunos, dentro e fora da escola, em cruzados de preceitos higiênicos e da aquisição de hábitos sadios" (SANTA CATARINA, 1942, p.120).

A partir de então, o ensino da higiene passou a ter outro significado: não caberia apenas ensinar na teoria os bons hábitos, mas era preciso fazer com que a escola fosse um grande laboratório. Tudo deveria formar uma grande consciência sanitária, sair do campo teórico e abstrato para alcançar o universo real da criança, ensinar-lhe hábitos saudáveis. Entendendo a infância como uma fase dividida, com periodizações, os médicos acreditavam que os hábitos deveriam ser inculcados na primeira e segunda infância, gerando, assim, uma vida saudável e feliz:

\begin{abstract}
A "existência feliz" e o "lisonjeiro porvir" justificam a periodização da vida, e, mais que isso, funcionaram como argumento para que a racionalidade médica se debruçasse sobre a "flor da infância", de modo que se construísse um discurso especializado a respeito desse período, do qual se poderiam extrair regras para assegurar a continuidade da vida, afastando, com isso, as crianças das práticas rudes, cujos sujeitos por eles responsáveis eram convertidos, pela lógica da ciência, em ignorantes, curiosos e indiscretos. Esse movimento da racionalidade médica, procurando instituir as verdades da ciência ou da razão, ao acompanhar a lógica da natureza, encontra-se igualmente atento aos problemas da cultura. [...] ao discorrerem sobre o problema da infância, torna-se perceptível a preocupação desses homens com as crianças submetidas a condições desiguais (GONDRA; GARCIA, 2004, p. 72).
\end{abstract}

Por meio da educação higiênica das crianças, os mestres influenciariam os pais e outros adultos para adquirirem bons hábitos e atitudes, comprovando-se, assim, o aspecto social da educação da saúde na família e na comunidade (LEX, 1953).

\title{
2. A fundação dos Pelotões de Saúde
}

Pela perspectiva de que para ter uma vida feliz era necessário ter saúde, o governo do estado recomendou, com muita insistência, que todos os estabelecimentos de ensino de Santa Catarina formassem e fundassem seus pelotões de saúde. Após a publicação da Circular $\mathrm{n}^{\circ}$

\begin{tabular}{l|l|l}
$\mathrm{v} .11$ & $\mathrm{n} .2$
\end{tabular}


26, em 19 de março de 1941, as escolas que institucionalizaram os pelotões de saúde estavam distribuídas em 20 cidades do estado catarinense, entre elas: Araranguá, Brusque, Camboriú, Campos Novos, Canoinhas, Criciúma, Harmonia, Florianópolis, Jaraguá, Itajaí, Joinville, Lages, Navegantes, Nova Trento, Parati, Porto Belo, Rodeio, São José, São Francisco, Timbó. As escolas que primeiro fundaram os pelotões de saúde, a partir de 1941, estavam inseridas na perspectiva de progresso e melhoramentos urbanos. Eram as cidades maiores, mais desenvolvidas e que estavam próximas à faixa litorânea do estado.

Nos anos 1940/1941, a matrícula e a frequência das crianças nas escolas primárias aumentaram significativamente no estado. A partir de 1940, as escolas isoladas foram dando lugar aos grupos escolares, que chegavam ao número de 505. A orientação do governo era instalar grupos em todas as localidades onde a densidade da população o justificasse.

Para a criação das associações de saúde nas escolas analisadas de Santa Catarina, realizavam-se reuniões entre alunos, professores e diretores para eleger as crianças que formariam os pelotões e os subpelotões. As reuniões se iniciavam, geralmente, com algum hino, poesias e/ou canções. Depois disso, os professores ou diretores liam a Circular $\mathrm{n}^{\mathrm{o}} 26$, de 19 de março de 1941, expedida pelo Departamento de Educação e, em seguida, os alunos liam a ata anterior para ser aprovada por todos os membros.

A escolha dos membros era realizada por meio de eleições, por indicação, por aclamação, pelo desempenho, ou se escolhiam os alunos que apresentassem melhor asseio. Após a escolha dos membros, os inspetores escolares ou as professoras regentes encarregavam-se de repassar as instruções e as obrigações às crianças. Em seguida, os inspetores colocavam-se ao lado dos alunos monitores para ensinar-lhes suas atribuições, entregando-lhes a bandeira do pelotão, que consistia numa flâmula branca com a dística Saúde, Força e Alegria e a cruz vermelha na parte inferior, sob aclamação de todos os alunos. Cabe destacar que as bandeiras eram confeccionadas pelos próprios alunos.

A escolha dos membros, ou diretoria dos pelotões, acontecia sempre no início do ano letivo. De acordo com a Circular no 26 de, 19 de março de 1941:

O aluno considerado monitor responsabilizar-se-á por um subpelotão pelo qual velará, ocupando-se diariamente na verificação do asseio de seus discípulos, ensinando-lhes como se escovam os dentes, passando-lhes em revista as unhas, o 
cabêlo, promovendo visitas ao dentista e ao médico quando necessárias. Cada criança que se notar em condições de ser monitora será indicada para tal e receberá as devidas instruções decorrentes da promoção (SANTA CATARINA, 1941, p. 120).

Como se verifica acima, a principal finalidade desses pelotões consistia no ensino da higiene e da educação sanitária, com a participação ativa dos próprios alunos dentro e fora da escola, de modo a se propor e adquirir hábitos sadios de higiene. As reuniões aconteciam mensalmente, para que os alunos que desejassem falar sobre a higiene fossem ouvidos. As reuniões mensais aconteciam depois do recreio; as atas eram escritas pelas próprias crianças. Ao final, tais atas deveriam ser assinadas por todos os presentes e remetidas, em duas vias, ao Departamento da Educação e à Inspetoria Escolar, cargo que então, 1941, era ocupado por Pedro Paulo Philippi. As atas deveriam conter em seus relatórios os nomes de todos os alunos nomeados, assim como seus cargos, data de fundação do pelotão, movimentos mensais e o nome do patrono, preferencialmente entre os dias 25 e 30 de cada mês. Os cargos eram hierárquicos e dividiam-se em: diretor ou presidente, secretária, monitores ou zeladores (asseio interno e externo), enfermeiras, caçadores de mosquitos. Entre seus membros, também se poderiam encontrar pessoas das comunidades.

As reuniões mensais também serviam para propor que trabalhos deveriam ser feitos pelos alunos. Após as explicações, a secretária entregava à monitoria, semanalmente, a relação dos trabalhos executados.

Na Circular n. 33, de 12 de março de 1942, observa-se como as associações escolares eram fiscalizadas e controladas pelo estado, com a cobrança de receber as fichas mensais no Departamento de Educação para acompanhar seu desenvolvimento.

Figura 2: Circular no 33 de 12 de março de 1942 
Revista Triângulo

ISSN 2175-1609
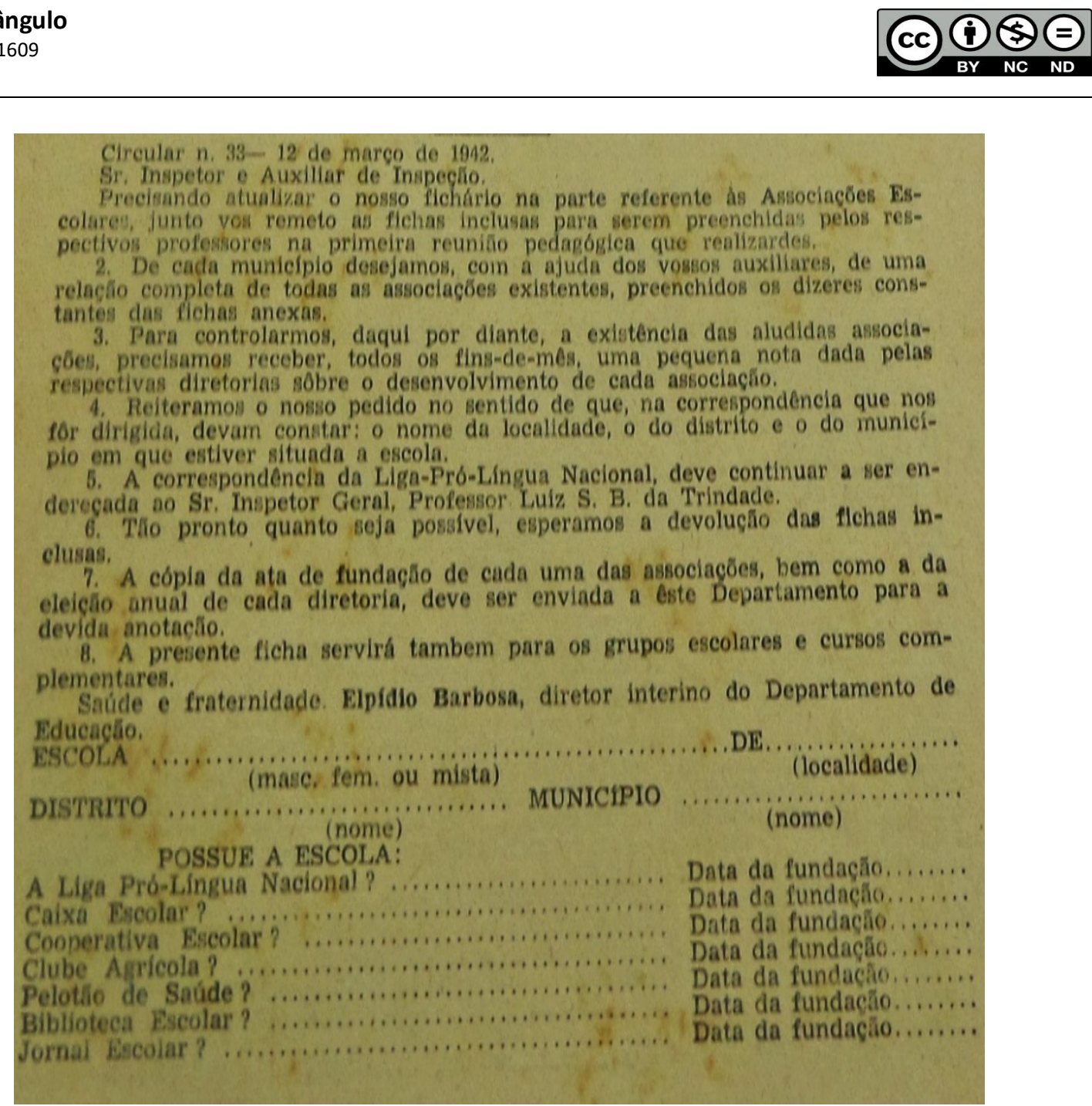

Fonte: Relatórios dos Pelotões de Saúde, 1942, p.17-18

Localização: Acervo Apesc.

A partir de 1942, o Departamento de Educação aprovou a representação do professor João dos Santos Areão para atuar como inspetor geral das associações auxiliares da escola. A Inspetoria Geral, através da Circular $\mathrm{n}^{\circ}$ 94, de 21 de outubro de 1942, exigia que fosse remetido, na primeira quinzena de dezembro, um questionário por todas as associações escolares, conforme se observa no documento abaixo:

Figura 3: Questionário anexo enviado aos pelotões de saúde 


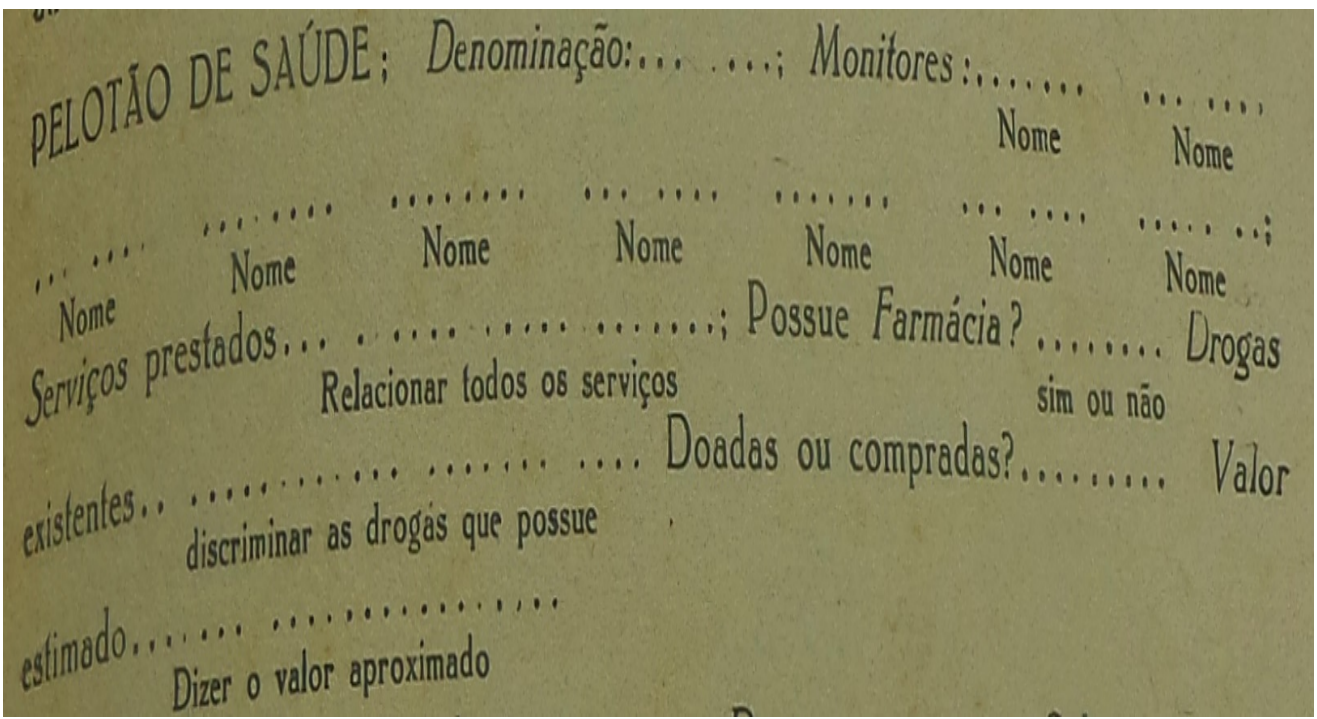

Fonte: SANTA CATARINA, 1942, p.67.

Localização: Acervo Apesc.

O questionário servia de referência para os pelotões de saúde e ao mesmo tempo era um modo de fiscalizar o trabalho realizado pelas crianças.

$\mathrm{O}$ presente inquérito tem a finalidade de podermos levantar tudo quanto temos realizado com referência às Associações Escolares e oferecer dados que sejam a expressão da verdade dêsse grande trabalho. Para tanto, chamamos a atenção dos dirigentes de Associações no sentido de as atas de reuniões e as atividades de cada uma serem registradas em livros, para que não haja, de futuro, alegação da sua não existência. O enfraquecimento das atividades sociais infantis é a prova de um trabalho mal orientado pelo professor e denota desânimo; por isso, cada associação criada precisa ir avante, oferecendo sempre um aspecto novo de sua vida. A escola que não possue, pelo menos, uma associação, não deu ainda sinal de que está em caminho de sua evolução e não despertou para essa vibração que todos precisamos experimentar. Para os grupos escolares remetemos três vias da presente ficha, sendo uma para ser devolvida logo estejam completos os seus dizeres; outra para acompanhar o relatório e a última para o arquivo do estabelecimento. As escolas isoladas devem devolver as fichas logo estejam elas convenientemente escrituradas. Todos os senhores diretores de estabelecimentos de ensino e professores de escolas isoladas devem atender, com o máximo cuidado, à escrituração da presente ficha, bem como à sua remessa tão logo lhes seja possível (SANTA CATARINA, 1942, p.66).

As diretorias explicavam aos ocupantes dos outros cargos que as fundações dos pelotões de saúde trariam inúmeros benefícios e que deles resultariam várias conveniências. Os alunos eleitos, ou escolhidos, para fazer parte dos pelotões eram do $1^{\circ}$ ao $4^{\circ}$ ano primário; 
geralmente, os mais velhos encarregavam-se das ações mais importantes, mas isso não era uma regra. Os subpelotões eram poucos; quando existiam, tinham a missão de fiscalizar o modo de acondicionar o lanche dos colegas:

Os monitores nem sempre terão sub-pelotão a dirigir, e distribuir-se-ão em grupos de zeladores pela limpeza do prédio, obrigados, cada um num setor, à entrega da casa em boas condições de ordem de um turno a outro. Entender-se-ão com os serventes, se preciso; serão ouvidos e sugerirão medidas para melhoria dos serviços de asseio (SANTA CATARINA, 1941, p. 120).

Entendia-se então que as atividades mais aconselháveis em favor da saúde do escolar seriam: a revista diária, a observação da conduta na escola, o inquérito sobre a vida no lar e o ensino das práticas úteis.

\section{Campanhas, rifas e prendas}

As escolas nas quais estavam inseridos os pelotões eram, em sua maioria, muito pobres e localizavam-se nas zonas rurais. Muitas delas relatavam que não conseguiam fundar os pelotões de saúde devido à falta de medicamentos, pois os alunos eram muito pobres e não tinham condições de colaborar. O estado, que havia proposto a implantação dos pelotões, não prestava assistência às escolas, que ficavam na dependência dos alunos que, raras vezes, pagavam as mensalidades no valor de $\mathrm{Cr} \$ 1,00, \mathrm{Cr} \$ 0,20$ ou $\mathrm{Cr} \$ 0,10$ centavos. Os pelotões recebiam doações dos pais dos alunos, dos professores, dos farmacêuticos, dos cursos complementares, dos comerciantes locais, dos grupos escolares e arrecadavam com as festas. Também faziam pedidos a laboratórios, hospitais e ao governo, que geralmente se excluía das questões relativas aos pelotões.

A forma mais comum que os monitores encontravam para angariar fundos para financiar a compra de medicamentos e materiais para os pelotões era através das rifas. Sortear algo de valor foi a forma mais utilizada para manter o número mínimo de remédios para atender às crianças que mais necessitavam, os professores e as pessoas das localizações próximas, lembrando que a maioria das escolas se localizava em lugares distantes e em meios rurais de difícil acesso a farmácias e hospitais. Muitas famílias dependiam dos medicamentos disponíveis nos pelotões de saúde das escolas. Alguns desses cediam remédios para os 
alunos, mas os vendiam para os pais. As rifas, semanas e campanhas que os monitores organizavam, geralmente sorteavam as prendas fornecidas pelos próprios alunos e professores das escolas; quando faltavam medicamentos, eles os permutavam nas farmácias por vidros vazios. Alguns pelotões tinham dívidas com as farmácias; para pagá-las, utilizavam as rifas. Algumas tinham cofres nas salas de aula, que eram abertos uma vez ao mês. A sala que tivesse mais dinheiro ganharia um prêmio.

Na ata de reunião da Escola Estadual de Gerivá, de 28 de julho de 1944, a professora agradece a colaboração dos alunos:

Esta associação, bem como as demais associações, muito tem contribuído para o desenvolvimento e educação das crianças que, com grande interesse trabalham, auxiliando na compra dos medicamentos, com as rifas que foram promovidas mensalmente pelas prendas oferecidas por eles (SANTA CATARINA, 1944, p. 23).

As campanhas, rifas e semanas eram realizadas pelos alunos com a finalidade de reverter em renda para a compra de medicamentos para os pelotões de saúde. Entre elas, destacam-se: campanha do vidro; campanha da borracha; campanha do jornal; campanha do papel velho; campanha do melado; campanha da bolinha de vidro; campanha do ferro; campanha do centavo; campanha do óleo; rifa de bola; rifa de porta-joias; rifa de estojo; rifa de copo; rifa caixa de segredo; rifa de lata de goiabada; rifa de vaso; rifa de cinzeiro; rifa de caixa de sabonete; rifa de sapatinhos de lã; semana do ovo; semana do ferro velho; semana do remédio, entre outras.

\section{As associações e caixas escolares}

No ano de 1941, as associações auxiliares da escola passaram por uma reorganização. Eram feitas reuniões para orientar e conseguir dos pais dos alunos apoio para as diferentes associações escolares. O poder público raramente ajudava as escolas catarinenses e cada qual enfrentava os problemas de acordo com suas condições, geralmente precárias, devido à pobreza. As associações escolares trouxeram a assistência necessária, atuando de diversas formas. 
As chamadas associações auxiliares apareceram no cenário da reforma da instrução pública a partir de 1911, representada por Orestes Guimarães, no governo Vidal Ramos. Naquele momento, o método que predominava era o intuitivo - "ícone da pedagogia moderna" -, que valorizava o papel dos sentidos da criança em seu processo de aprendizagem, incorporando as chamadas lições de coisas, por meio das quais se estimulavam as crianças a observar os fenômenos estudados ou suas representações por meio de imagens, entre outros recursos (TEIVE, 2008, p. 65).

A partir de 1941, Elpídio Barbosa, superintendente geral interino do ensino, publicou a Circular $n^{\circ}$ 5, em 6 de janeiro de 1941, na qual explicava a respeito dessas associações:

Aos srs. Inspetores escolares, diretores de grupos escolares e professores de escolas isoladas. Assunto: sobre associações auxiliares da escola. Recomendo-vos, com muita insistência, sejam organizadas nos estabelecimentos de ensino associações, tais como: clube agrícola, pelotão de saúde, jornal, liga de bondade, liga pró-língua nacional, biblioteca, círculo de pais e professores, clube de leitura etc. etc., realizando assim os objetivos a que desejamos alcançar: - 1) preparar o indivíduo a viver em sociedade; 2) tornar o indivíduo guia de si mesmo; 3) ensinar o valor da cooperação; 4) despertar o interêsse ${ }^{3}$ do educando pela escola; 5) despertar no educando os sentimentos de ordem e legalidade; 6) desenvolver certas qualidades: iniciativa, liderança, características pessoas e habilidades. Os srs. Inspetores escolares deverão cientificar à Superintendência as necessidades encontradas na execução da presente circular, especialmente quando diretores e professores se mostrarem infensos à criação dessas associações (SANTA CATARINA, 1941, p. 70-71).

A resistência em implantar tais associações nas escolas era grande por parte de muitos professores. Eles reclamavam que tinham muito serviço e as associações os sobrecarregavam; porém, não compreendiam que eram organizadas para que os próprios alunos delas tomassem conta, cabendo a eles (professores) apenas a função de auxiliar, não devendo tomar para si as responsabilidades que eram dos alunos, pois o objetivo era preparar as crianças para viver em sociedade, conforme citado na Circular $\mathrm{n}^{0}$ 5, supracitada: "Os professores devem trabalhar com mais afinco a fim de conseguirem melhores resultados. Todo o trabalho deve ser feito exclusivamente pela criança" (SANTA CATARINA, 1942). Continuava o texto:

A respeito das associações escolares, foram dadas amplas instruções acerca da marcha que deve ser seguida no desenrolar de suas respectivas atividades. Cada

\footnotetext{
${ }^{3}$ Grafia mantida do documento original.
} 
professora deve assumir completamente a responsabilidade do andamento daquela associação que lhe foi confiada. As referidas sessões mensais devem ser concebidas e elaboradas pelos próprios alunos, que assim irão progressivamente melhorando e aperfeiçoando seus trabalhos (SANTA CATARINA, 1943, p. 54).

Destacam-se, na citação abaixo, a insistência do inspetor Germano Wagenfihr e a resistência dos professores:

\begin{abstract}
Solicitou o sr. Inspetor Germano Wagenfihr que os diretores e professores prestassem o melhor apôio e interesse, afim de que sejam organizados, conforme prevê o regulamento em vigor. A cooperação do professor nas instituições em referência deve ser real e imediata. A missão precípua do mestre é educar em todos os sentidos. O desânimo, a má vontade não são apanágios do educador sincero e justo (SANTA CATARINA, 1941, p.145).
\end{abstract}

Muitos professores reclamavam das associações escolares e demonstravam não ter confiança nos trabalhos das crianças, o que levou Elpídio Barbosa a publicar considerações de autoridade escolar sobre as associações escolares na Circular n.108, de 5 de dezembro de 1942. Observa-se, no texto, a preocupação com o papel exemplar do professor na formação moral das crianças. Além disso, enfatizava que as instituições não teriam sido criadas para os professores e, sim, para as crianças.

As instituições escolares têm produzido ótimos resultados no ensino, principalmente nos estabelecimentos onde docentes e discentes bem compreenderam a utilidade das mesmas. Há grupos, porém, em que o diretor fundou instituições e exige o trabalho só do professor e o nome do aluno figura somente para a satisfação dos regulamentos. Não trabalhando o aluno, não haverá produção e nem tampouco proveito. As instituições não foram feitas para os professores, e sim para a criança, preparando-a, como é o lema desse Departamento "para a vida e pela vida", e daí a reclamação de alguns diretores, e mesmo professores, de se acharem sobrecarregados de serviços. Alguns, até, me objetaram, quando lhes apresentava em reunião, o erro acima apontado, dizendo: "nós não temos confiança no serviço dos alunos, principalmente na Cooperativa". Esta desconfiança, por parte do superior, é ainda mais grave. A criança, que é psicológica por natureza, nota perfeitamente o pensamento do diretor ou professor e tira daí as suas conclusões maliciosas. Assim sendo, o responsável, involuntariamente, estará cooperando para a formação de homens moralmente defeituosos. O capital é do aluno; e quem melhor que o próprio dono saberá dirigir os seus negócios? O diretor faz compras para a Cooperativa. Não está certo, pois êle somente poderá orientar e não intervir'.

Na reunião do pelotão de saúde do Grupo Escolar Prof. Paulo Schieffler, em 28 de maio de 1941, o diretor expõe a problemática da resistência dos professores às associações

\begin{tabular}{l|l|l} 
v.11 & $\mathrm{n} .2$
\end{tabular}


Revista Triângulo

ISSN 2175-1609

escolares, o que era muito preocupante, pois o professor era considerado um exemplo a ser seguido pelas crianças:

Referente às associações auxiliares da escola, tidas como tais e não como uma sobrecarga para o professor, que toma para si o trabalho que deveria fazer o aluno, para sua própria instrução. Daí, muitas vezes, o professor queixa-se de excesso de trabalho, que chega mesmo a invadir seus poucos momentos de lazer. Tal acepção é errônea e o professor esquece que ele é apenas orientador e que os alunos é que executam os trabalhos, embora não os apresentem perfeitos e sem falhas (SANTA CATARINA, 1941, p. 65).

Os poucos pelotões de saúde que existiam nas escolas catarinenses foram criados com muitas dificuldades, principalmente por causa dos preços dos remédios, que eram muito caros. Várias escolas fundaram tardiamente os pelotões, principalmente as mais distantes.

O pelotão de saúde foi fundado, lutando, porém, com muita dificuldade, não tendo ainda o equipamento necessário, por motivo da escassez de recursos obtidos dos pais dos alunos, esperando, porém, que em 1943, entre numa fase de prosperidade, como as demais instituições (SANTA CATARINA, 1942, p. 32).

Mesmo com a constante recomendação do estado na implantação das associações escolares, muitas demoraram anos para instalar os pelotões de saúde e entender suas finalidades. A Circular n. ${ }^{\circ}$ 2, de 2 de janeiro de 1942, assinada por Elpídio Barbosa, relata um tópico de um inspetor escolar sobre essas associações:

Quanto a estas, devo dizer que em certo número de grupos se deu perfeito funcionamento às mesmas, mas grande número não tinha compreendido a finalidade da maioria destas instituições, por isso fiz ver a exigência capital: que os alunos é que deviam realizar todos esses serviços e que os professores só deviam ser orientadores ou animadores, e só em caso de desconhecimento de um ou outro ato, deviam auxiliá-los. Além disso, nessas instituições o maior número possível de alunos tomasse parte das diretorias, a fim de que esses aprendessem, para a vida futura, como se dirige uma sociedade; quais os deveres e trabalhos dos diretores; como se faz uma ata, como se preside uma reunião etc., e que tudo isso seja afinal, a vida social em miniatura. A outra finalidade seria a de fazer os educadores compreenderem a necessidade do espírito de cooperação, de amor ao próximo, assistência mútua, do desenvolvimento intelectual e finalmente a cooperação dos alunos na nacionalização de si próprios, seus colegas e sua própria família (SANTA CATARINA, 1942, p. 3-4). 
Revista Triângulo

ISSN 2175-1609

As criações das caixas escolares foram regulamentadas pelo Decreto n. ${ }^{\circ} 976$, de 14 de novembro de 1916. Quando os pelotões de saúde não conseguiam angariar fundos para suprir suas necessidades através das rifas, campanhas ou semanas, recorriam às caixas escolares:

Usando a palavra nosso mestre fez ressaltar a falta de recursos que a nossa escola se acha no momento. Situada num bairro completamente pobre, luta no momento a nossa escola com grandes dificuldades. Isto impéde ${ }^{4}$ no entanto que nosso pelotão tenha o necessário material para seu desenvolvimento. Sei perfeitamente desse nosso mestre que qualquer autoridade que visitar a nossa escola terá má impressão da sala de aula, mas uma pergunta faço, onde adquirir dinheiro para a compra de material e melhor mobiliário? Mas isto não impede à boa marcha nos nossos trabalhos diários, o que a caixa escolar recebe de seus associados (SANTA CATARINA, 1941, p. 83).

Alguns pelotões possuíam sua própria farmácia, que prestava inúmeros socorros e eram mantidas pelas caixas escolares, que, por sua vez, tinham a obrigação de suprir as necessidades médicas, dentárias e farmacêuticas das escolas, conforme publicado no art. 29 da Circular $n^{\circ}$ 19, de 6 de março de 1941. Quanto ao orçamento e à execução das caixas escolares, a mesma circular dispunha a ordem a seguir:

$\mathrm{Na}$ aplicação dos recursos da Caixa, obedecer-se-á, quanto as despesas, rigorosamente, à seguinte ordem de preferência: a) expediente da Caixa, merenda, roupa e calçado; b) livros didáticos e material escolar; c) assistência médica, dentária e farmacêutica; d) prêmios escolares (SANTA CATARINA, 1941, p. 104).

Apesar de o orçamento colocar a assistência médica, dentária e farmacêutica em terceiro lugar, observamos, no decorrer do trabalho, que as questões do material didático, dos prêmios escolares, da roupa, dos calçados e da alimentação estão intimamente ligadas ao pelotão de saúde e aos preceitos higienistas.

\section{CONSIDERAÇÕES FINAIS}

Identificamos, nesta pesquisa, que os pelotões de saúde implantados pelo estado de Santa Catarina desenvolveram uma missão filantrópica nas escolas primárias. O governo,

\footnotetext{
${ }^{4}$ Grafia mantida do documento original.
} 
negligente, deixou a responsabilidade de disseminar a higiene para as crianças e os professores, que trabalharam com afinco para consolidar o plano de civilidade e progresso do país. Isto explica por que muitas escolas demoraram para conseguir fundar seus pelotões, posto que as crianças eram muito pobres e não tinham condições de adquirir a medicação mínima para socorrê-las e ampliar os atendimentos nas escolas.

Os pelotões desenvolveram uma dupla função nas escolas: a de disseminar as práticas higienistas e a de curar, ou medicar, as crianças e principalmente a população que se encontrava nas regiões mais pobres e nas zonas rurais. Esta medicalização, nem sempre autorizada pelo Departamento de Educação, ajudou a diminuir o índice de moléstias graves que assolavam o Brasil na década de 1940, como a malária, a febre amarela e o tifo, entre outras.

As associações e os pelotões de saúde tiveram papel fundamental na construção de gerações mais saudáveis e conscientes das condições higiênicas, ajudando a diminuir a mortalidade infantil, embora estivessem envolvidas sob um manto que as conformavam aos valores e princípios de governos autoritários, que encontravam na educação o espaço ideal de aproximação com as famílias, e assim difundir os princípios por eles defendidos.

\section{REFERÊNCIAS}

BARBIERI, Iris. A educação no governo Vargas: 1930-1945, com ênfase no ensino normal e na escola primária. 1973. Tese (Doutorado) - Faculdade Municipal de Ciências Econômicas e Administrativas de Osasco/SP,1973.

BASTOS, Nilo Chaves de Brito; SILVA, Orlando Junior. Programas educativos nas unidades sanitárias do Serviço Especial de Saúde Pública. Revista do Serviço Especial de Saúde Pública, v. 6, n. 1, 1953. p. 219-284.

CABRAL, Oswaldo Rodrigues. Problemas educacionaes de hygiene. Trabalho apresentado com o fim de obter grau de doutor em medicina, 1929.

FARIA, Lina. Educadoras Sanitárias e Enfermeiras de Saúde Pública: identidades profissionais em construção. Cadernos Pagu (27), jul./dez/ 2006: pp.173-212.

GONDRA, José Gonçalves. Artes de Civilizar, Medicina, Higiene e Educação escolar na Corte Imperial. EDUERJ, Rio de Janeiro, 2004. 
GONDRA, José; GARCIA, Inára. A arte de endurecer miolos moles e cérebros brandos’: a racionalidade médico-higiênica e a construção social da infância. Revista Brasileira de Educação. mai./ jun./jul./ago. no 26, 2004.

LAROCCA, Liliana Muller. Higienizar, cuidar e civilizar: O discurso médico para a Escola Paranaense (1886-1947). 2009.Tese (Doutorado) - Universidade Federal do Paraná, Curitiba/PR.

LEX, Ary. Biologia Educacional. Companhia Editora Nacional, São Paulo, 1953.

SANTA CATARINA. Circular n.108, de 5 de dezembro de 1942. Acervo do Arquivo Público do Estado de Santa Catarina.

SANTA CATARINA. Ata de Reunião de 28 de maio de 1941. Acervo do Arquivo Público do Estado de Santa Catarina.

SANTA CATARINA. Ata de Reunião de 28 de julho de 1941. Acervo do Arquivo Público do Estado de Santa Catarina.

SANTA CATARINA. Decreto n. 976, de 14 de novembro de 1916. Acervo do Arquivo Público do Estado Santa Catarina.

SANTA CATARINA. Circular n. 26, de 19 de março de 1941. Acervo do Arquivo Público do Estado de Santa Catarina.

SANTA CATARINA. Circular n. 33 de 12 de março de 1942. Acervo do Arquivo Público do Estado de Santa Catarina.

SANTA CATARINA. Circular n.76, de 16 de março de 1943. Acervo do Arquivo Público do Estado de Santa Catarina.

SANTA CATARINA. Circular n. 2, de 2 de janeiro de 1942. Acervo do Arquivo Público do Estado de Santa Catarina.

SOUZA, Rosa Fátima de. História da organização do trabalho escolar e do currículo no Século XX: ensino primário e secundário no Brasil. São Paulo: Cortez, 2008.

TEIVE, Gladys Mary Ghizoni. "Uma vez normalista, sempre normalista": cultura escolar e produção de um habitus pedagógico (Escola Normal Catarinense - 1911/1935). Florianópolis: Insular, 2008. 